\title{
Örgüt Kültürünün Örgütsel Sinizme Etkisi: Karacabey İlçesi Gıda Sektörü Üzerine Uygulama
}

\author{
Edip ÖRÜCÜ* \\ Ömer GIZZLIER ${ }^{\dagger}$ \\ Ahmet NAZIR
}

$\ddot{O} \mathbf{z}$

Bu araştırmanın amacı örgüt kültürünün örgütsel sinizme etkisini incelemektir. Araştırmadaki veriler 2019 yılının Kasım ayında yüz yüze anket yöntemiyle toplanmıştır. Bu doğrultuda Bursa ilinin Karacabey ilçesi içerisinde gıda sektöründeki 5 firma çalışmanın evreni, bu firmaların herhangi bir biriminde çalışan toplam 117 kişi rastgele seçilerek çalışmanın örneklemini oluşturmuştur. Ancak 7 ankette eksik veya yanlış bilgi olduğu için çalışmaya 110 anket dâhil edilmiştir. Çalışmanın sonucunda örgüt kültürü ile örgütsel sinizm arasında negatif bir ilişki olduğu görülmüştür. Bununla beraber örgüt kültürü alt boyutlarından güç kültürü ve başarı kültürü örgütsel sinizmi açıklamada anlamlı katkı sağladığı ancak destek kültürü ve hiyerarşi kültürünün anlamlı katkı sağlamadığı tespit edilmiştir. Ayrıca örgütsel sinizm ile güç kültürü arasında pozitif bir ilişki, örgütsel sinizm ile başarı kültürü arasında ise negatif bir ilişki olduğu saptanmıştır.

Anahtar Kelimeler: Örgütsel Sinizm, Örgüt Kültürü, Gıda Sektörü.

\section{The Effect of Organizational Culture on Organizational Cynicism: Application on Food Sector in Karacabey District}

\begin{abstract}
The aim of this research is to examine the impact of organizational culture on organizational cynicism. The data in the research were collected by face to face survey method in November 2019. In this respect, 5 companies which is on the food sector in Bursa city-Karacabey district were selected for population. 117 people were selected randomly who works in any units of these companies for a sample of the study. However, 110 surveys were included in the study because there was incomplete or incorrect information in 7 surveys. The results of the study showed a negative relationship between organizational culture and organizational cynicism. However, it has been found that the power culture and success culture from the lower dimensions of organizational culture contribute significantly to explaining organizational cynicism, but the support culture and hierarchy culture do not contribute significantly. It has also been seen to have a positive relationship between organizational cynicism and power culture, and a negative relationship with success culture.
\end{abstract}

Key Words: Organizational Cynicism, Organizational Culture, Food Industry.

Received/Geliş: 23.01.2020

Accepted/Kabul: 18.05.2020

Araştırmadaki anket çalışması 2019 yılının Kasım ayında gerçekleştirildiği için geriye dönük etik kurul izni bulunmamaktadir.

\footnotetext{
* Prof. Dr., Bandırma Onyedi Eylül Üniversitesi, İktisadi ve İdari Bilimler Fakültesi, İşletme Bölümü, Yönetim ve Organizasyon ABD, eorucu@ bandirma.edu.tr, (D/0000-0002-3301-7496

$\dagger$ Arş. Gör., Bandırma Onyedi Eylül Üniversitesi, İktisadi ve İdari Bilimler Fakültesi, İşletme Bölümü, Yönetim ve Organizasyon ABD, ogizlier@bandirma.edu.tr, D/0000-0002-5745-8800

* Yüksek Lisans Öğrencisi, Bandırma Onyedi Eylül Üniversitesi, Sosyal Bilimler Enstitüsü, İşletme Tezli Yüksek Lisans Program1, ahmetnazir13@gmail.com, D/0000-0002-1635-1492

(Makale türü: Araştırma makalesi)
} 


\section{Giriş}

Örgütsel sinizm hem yurt dışında hem de ülkemizde ilgi görmüş bir kavramdır. Örgütsel sinizm çalışanın örgütüne karşı olumsuz bir tutumu olarak tanımlanır (Dean, Brandes ve Dharwadkar 1998). Günümüzde örgütsel sinizmin yüksek olduğu firmalarda çalışanların olumsuz etkilendiği gözlemlenmektedir. Hem ülkemizde hem de yurt dışında örgütsel sinizme etki eden kavramlar araştırılmıştır ve araştırılmaya devam edilmektedir. Bu kavramlardan bir tanesi de örgüt kültürüdür. Örgüt kültürü, çalışanların davranışlarını yönlendiren ve sınırlayan bir dizi yapı, rutin, kural ve normlar olarak tanımlanır (Schein, 2004). Bu çalışma örgüt kültürünün örgütsel sinizme etki edip etmediğini öğrenmeye yöneliktir. Bu araştırmanın gerekçesi ise, örgütsel sinizm ile örgüt kültürü arasındaki ilişkiye duyulan önemin giderek artmasıdır.

Çalışmanın birinci bölümünde araştırmada yer alan değişkenlerin tanımları yapılarak, kavramsal çerçeve ortaya konmuştur. Çalışmanın ikinci bölümünde örgüt kültürü ve örgütsel sinizm değişkenlerini içeren çalışmaların olduğu literatür taraması yer almaktadır. Üçüncü bölümünde araştırmada kurulan hipotezler, araştırma modeli, araştırmanın evreni ve örneklemi, araştırmada kullanılan ölçekler, ankete ait bilgiler vardır. Dördüncü bölümde araştırmada elde edilen verilerin analizi sonucu tespit edilen bulgular sunulmuştur. Verilerin analizinde betimsel istatistikler, güvenilirlik, korelasyon ve regresyon analizleri kullanılmıştır. $\mathrm{Bu}$ analizler doğrultusunda hangi hipotezlerin kabul edildiği hangilerinin reddedildiği ifade edilmiştir. Son olarak çalışmanın sonuç bölümünde ise, çalışmanın sonucunda elde edilen bulgular ve bu bulguların yorumlanması, önceki çalışmalarla kıyaslanması, çalışmadaki kısıtlar ve gelecek araştırmacılara öneriler vardır.

\section{Kavramsal Çerçeve \\ Örgütsel Sinizm}

Çalışanın örgütüne karşı olumsuz bir tutumu olarak tanımlanır. Çalışanlar, örgütlerinde bazı eksiklikler olduğunu düşünür ve bu eksiklikler örgüt için küȩük düşürücü ve hassas olma eğilimindedir. $\mathrm{Bu}$ durumun örgüt üzerinde olumsuz etkileri vardır (Dean ve diğer. 1998). Siniklerin bazı özellikleri sürekli şikayetler, örgütün ve meslektaşlarının küçümsenmesi, sürekli kötümser ifadeler ve örgüt tarafından hile hissi olarak listelenebilir (Abraham, 2000).

\section{Örgüt Kültürü}

Bir grup tarafından icat edilen ya da dışsal adaptasyon ve içsel bütünleşmenin problemlerine çare bulmak için öğrenirken keşfedilen ve yeteri kadar geçerli sayılabilecek kadar iyi çalışan temel bir varsayım modelidir. Bu sebeple, örgütün yeni üyelerine bu problemlerle ilgili olarak algılamanın, düşünmenin ve hissetmenin doğru yolu olarak öğretilmesidir. Schein'a göre kültür diğerleri arasındaki etkileşimden kaynaklanan ve liderlik davranışları tarafından 
desteklenen dinamik bir süreçtir. Kültür, davranışları yönlendiren ve sınırlayan bir dizi yapı, rutin, kural ve normları kapsar (Schein, 2004).

\section{Örgüt Kültürünün Boyutlarından Güç Kültürü}

Örgüt içerisinde çalışanların sınıflandırılmasının ön planda olduğu, güce belirli kişilerin sahip olduğu örgüt kültürü tipini ifade eder. Güç, itaat, denetim gibi kavramlar önemlidir. Yetki çoğu zaman üst yöneticilerdedir. Yatay iletişim yerine dikey iletişim, örgüt içerisinde yer alır. Otoriter bir yönetim anlayışı hakimdir (Terzi, 2000).

\section{Örgüt Kültürünün Boyutlarından Başarı Kültürü}

Kurallara uyulmasındansa daha çok işlerin yapılması ve başarıya önem verilen örgüt kültürü tipidir. Bu örgüt kültürü tipine örnek olarak araştırma enstitüleri ve danışmanlık şirketleri olabilir. Bu kültür tipinde insanlar işleriyle ilgilidir ve onları tatmin edici görevlerde çalışmaktan hoşlandıkları varsayılmıştır (Şişman, 2002).

\section{Örgüt Kültürünün Boyutlarından Destek Kültürü}

$\mathrm{Bu}$ kültür tipinde çalışanların örgüt içinde düşünceleri önemsenir ve herkes kendini örgütün bir parçası olarak görür. Bu da örgüte ait bağl1lık ve aidiyet duygusu oluşturur. Başarı kültüründe lider, örgütünü yönlendirir ve çalışanların işe katılımını teşvik eder (Işık,2014).

\section{Örgüt Kültürünün Boyutlarından Hiyerarşi Kültürü}

Hiyerarşi kültür tipinde kuruma ait prosedürler, düzenlemeler ve resmi yapılaşma söz konusudur. Örgüt içinde kişilerin sahip olduğu roller, o kişilerden daha önemli algılanır. Dolayısıyla örgüt üyeleri bu rollere göre örgüt içinde tanımlanır (Işık, 2014).

\section{Literatür Taraması}

Narges Rabiea, Fatemeh Karimia ve Ali Naimi Sadigh (2016) tarafindan Tahran Ziraat Bankası'nda örgütsel sinizm oluşumu üzerine dönüşümsel liderlik tarzı ve örgüt kültürünün etkisi inceleyen bir çalışma kaleme alınmıştır. Bu çalışmanın amacı, Tahran Ziraat Bankası'nda örgütsel sinizm oluşumu üzerine dönüşümsel liderlik tarzı ve örgüt kültürünün etkisini değerlendirmektir. Araştırmanın evreni olarak Tahran Ziraat Bankası'nda çalışan 1022 kişi belirlenmiştir. Bu evren tanımına uyan 304 kişiye anket dağıtılmıştır ancak 264 tane anket geçerli sayılmıştır. Araştırma sonucunda dönüşümsel liderlik tarzının örgütsel sinizme herhangi bir etkisi olduğu görülmemiştir. Ancak örgüt kültürünün örgütsel sinizme olumsuz etkisi olduğu görülmüştür (Rabiea, Karimia ve Sadigh, 2016).

Omar Durrah, Monica Chaudhary ve Moaz Gharib (2019) tarafindan hazırlanan makalede endüstriyel örgütlerdeki örgütsel sinizm ve onun örgütsel gurura etkisi incelenmiştir. Bu çalışmanın amacı örgütsel sinizm ve örgütsel gurur arasındaki ilişkiyi bulmaktır. Bu amaçla 9 endüstri firmasına anket dağıtılmıştır. Çalışmanın örneklemi olarak bu firmalarda çalışan 350 kişi seçilmiştir. Çalışmanın sonucunda duygusal ve davranışsal sinizmin duygusal gurur üzerinde 
önemli ve olumsuz bir etkiye sahip olduğunu ortaya çıkarırken, bilişsel sinizmin duygusal gururu önemli ölçüde etkilemediği görülmüştür. Ayrıca örgütsel sinizmin alt boyutlarından olan duygusal sinizmin tutumsal gurur üzerinde önemli bir etkiye sahip olduğunu, bilişsel sinizm ve davranışsal sinizmin tutumsal gurur üzerinde önemli bir etkisi olmadığını ortaya çıkmıştır. (Durrah, Chaudhary ve Gharib, 2019).

Winfred O. Goromonzi (2016) tarafından hazırlanan bir çalışmada örgüt kültürü, strateji uygulaması ve Zimbabwe'deki ticari bankaların performansı incelenmiştir. Bu bağlamda Zimbabwe'den 15 ticari banka seçilmiştir. Bu bankaların her birinden beşer kişi seçilerek anket uygulanmıştır. Çalışmanın sonucunda maddi olmayan kaynakların bankaların faaliyet gösterdiği yere göre farklı etkileri olduğunu ortaya çıkartmıştır. (Goromonzi, 2016).

Nihat Kaya, Ercan Ergün ve Mustafa Kesen (2014) tarafindan insan kaynakları yönetimi uygulamalarının ve örgüt kültürü türlerinin örgütsel sinizm üzerine etkileri incelenmiştir. $\mathrm{Bu}$ çalışma, İnsan Kaynakları Yönetimi uygulamalarının ve örgüt kültürünün örgütsel sinizm üzerine etkisini araştırmayı amaçlamıştır. Araştırma evreni olarak Kayseri'de faaliyet gösteren 5 üretim firmasından 575 kişi olmuştur. Bunların 512'si geri dönmüş ancak çeşitli hata veya eksiklerin olduğu anketler çıkartılınca çalışmaya 479 anket dahil edilmiştir. Bu çalışmanın sonuçlarında davranış ve tutumların, kapsamlı eğitimin, çoklu işlevlerde eğitimin ve teşviklerin örgütsel sinizmi olumsuz etkilediğini görülmüştür. Buna ek olarak, otokrasi kültürünün örgütsel sinizm üzerinde önemli bir etkisi olduğu tespit edilmiştir (Kaya, Ergün ve Kesen, 2014).

Murat Görmen (2012) tarafindan yapılan bir çalışmada örgüt kültürünün örgütsel sinizme etkisi incelenmiştir. Bu araştırmanın amacı, tekstil sektöründe yer alan kişilerin örgüt kültürü, örgütsel bağlılık ve tükenmişlik arasındaki ilişkiyi belirlemektir. Araştırmada anket yöntemi ile veriler toplanmıştır ve bu anketler yüz yüze gerçekleştirilmiştir. Anket Kahramanmaraş’taki tekstil sektöründe çalışan 4000 kişi içerisinden rastgele seçilerek 380 kişiye yapılmıştır. Eksik cevaplanan anketler çalışmadan çıkarıldığı için 360 anket üzerinden analizler yapılmıştır. Araştırmanın sonucunda örgüt kültürünün örgütsel bağlılığa olumlu, örgütsel tükenmişliğe olumsuz etki ettiği anlaşılmıştır. Bununla birlikte örgütsel bağlılığın örgütsel tükenmişliğe olumsuz etkisi olduğu görülmüştür. Ayrıca örgütsel tükenmişliğe başarı hissi boyutunun olumsuz, duyarsızlaşma boyutunun olumlu etkisi olduğu anlaşılmıştır. Son olarak duygusal tükenmişlik boyutunun örgütsel tükenmişlik üzerinde olumlu etkisi olduğu anlaşılmış (Görmen, 2012).

Duygu Topal Yıldırım'ın (2016) hazırladığı çalışmada ise sağlı alışanlarına yönelik örgüt kültürünün örgütsel sinizm ile ilişkisi incelenmiştir. Bu çalışmanın amacı örgütsel sinizm tutumları ile örgüt kültürü algıları arasındaki ilişkiyi belirlenen hastanelerdeki sağlık personelleri üzerinden öğrenmektir. Bunun için hastane çeşidinin ve sayısının fazla olduğu İstanbul ili seçilmiştir. Yani anketin evreni İstanbul'da sağlık kurumlarında görev alan tüm çalışanlardır. 
Anket veri tekniğine başvurulmuştur ve anketler yüz yüze yapılmıştır. Örneklem olarak da farklı hastanelerde çalışan 186 sağlık personeli seçilmiştir. Çalışma sonucunda kurumda çalışanların örgüt tarafından insan olduğunun hissettirilmesi gerektiği vurgulanmıştır. Sonrasında örgüt kültürü oluşturulması ve bunun alınan kararlarda etkili olacağı fark edilmiştir. Ayrıca örgüt içi sayg1 ve sevginin, karar alınması ve uygulanması konusunda dengeli olması gerektiği belirtilmiştir. Bu denge çalışanın örgütüne olan aidiyet hissini sağlamlaştıracağı görülmüştür. Son olarak örgütte ödül sisteminin moral ve motivasyonu arttırmak için zaman zaman kullanılabileceği söylenmiştir (Topal Yıldırım, 2016).

Jermen Kantarcıoğlu (2016) tarafından yapılan çalışmada Ermeni Azınlık Okulları'nda çalışanların örgüt kültürü ve örgütsel sinizm ilişkisini incelenmiştir. Çalışmanın amacı, Ermeni Azınlık Okulları'nda örgütsel sinizm ile örgüt kültürü arasındaki ilişkiyi belirlemek ve değişkenlere göre ilişkinin değişip değişmediğini incelemektir. Çalışmada anket yöntemi kullanılmıştır. 2015-2016 eğitim ve öğretim yılında İstanbul'daki 16 Ermeni Azınlık Okulu'nda görevli olan öğretmenler anketin evreni olarak seçilmiştir. Sonrasında izin alınabilen 10 okuldaki öğretmenler anketin örneklemini oluşturmuştur. Ankete katılım sayısı 191'dir. Araştırma sonucunda örgüt kültürünün alt boyutlarından olan destek kültürü ile başarı kültürünün örgütsel sinizm ve alt boyutları ile ilişkili oldukları tespit edilmiştir. Ancak bürokratik kültür ile görev kültürünün aynı değişken ile bir ilişkisi görülmemiştir. Yani başarı ve destek kültürünün güçlü olması şartıyla örgütsel sinizmin azaltılabileceği sonucuna varılmıştır (Kantarcığlu, 2016).

Murat Görmen (2017) tarafından yazılan bir diğer çalışmada örgüt kültürünün örgütsel sinizm üzerine etkisi araştırılmıştır. Bu makalenin amacı, örgütsel sinizm ile örgüt kültürü arasındaki ilişkiyi incelemektir. İlişkinin olumsuz yönde olacağı tahmin edilmiştir. 5 örgütte çalışan kişiler araştırmanın evreni olmuştur. Bu örgütler bir özel sağlık ve kamu sağlık kurumu, bir fabrika, bir üniversite fakülte dekanlığ 1 ve bir bakanlığına ait birimdir. Belirtilen yerlerde çalışan sayısı 450 dolaylarındadır. Bu 450 kişiden 372 tanesi makalenin anket çalışmasına katılmıştır. Araştırmanın örneklemi ise bu evreni temsil etmesi için rastgele seçilen katılımcılardır. Araştırmada, bu kurumlarda çalışan 372 çalışandan anket yöntemi ile elde edilen veriler kullanılmıştır. Sonuç olarak örgütsel sinizm üzerinde örgüt kültürü ve boyutlarının etkili olduğu sonucuna varılmıştır (Görmen, 2017).

Ayhan Yalçınsoy’un (2019) hazırladığı çalışmada ise örgütsel sinizmin nedeninin örgüt kültürü olup olmadığı araştırılmıştır. Makalenin amacı çalışanların örgüte olan bağlılığını azaltan, performans düşüklüğüne sebep olan ve motivasyonlarını zayıflatan etmenin örgüt kültürü olup olmadığını incelemektir. Çalışmada veri elde etmek için anket yoluna başvurulmuştur. Anket, Gaziantep Organize Sanayi Bölgesinde yer alan kişilere dağıtılmış ve 256 anket analiz için kullanılmıştır. Makalede örgüt kültürün zayıflığı yukarıda saydığım durumları oluşturduğu 
görülmüştür ve yazar bu durumun önlenmesi için mücadele edilmesini gerektiğini eklemiştir. Çalışanların karlılık sürecine, iletişim organlarına dahil edilmesi gerektiğini ve ödül-ceza sistemin örgütsel sinizmi azaltacağını belirtmiştir (Yalçınsoy, 2019).

Esendal Güleç, İbrahim Halil Cankul ve Süreyya Yılmaz (2019) tarafindan örgüt kültürünün örgütsel sinizme etkilerini incelenmiştir. Çalışma içerisinde kamu ve özel hastanelerinin bu konuda karşılaştırılması yapılmıştır. Çalışmanın amacı, sağl1k sektöründe örgüt kültürünün sinizme etkilerini ortaya koymak ve bu etkilerin özel ve kamu hastaneleri arasında kıyaslamaktır. Çalışmanın evrenini 30 adet sağlık kurumu oluşturmaktadır. Sağlık kurumunun herhangi bir bölümünde çalışıyor olması ankete katılmaları için yeterli görülmüştür. Bu 30 kurum içerinde yer alan 1280 kişiye anket dağıtılıış ancak 771 tanesi geri dönmüştür. Çalışmanın sonucunda özel ve kamu hastanelerinin örgütsel sinizmi kıyaslanmıştır. Arada fark olduğu tespit edilmesine rağmen bu farkın anlamlı olmadığı görülmüştür. Yani kamu veya özel hastane olup olmadığına bakılmaksızın kuvvetli bir örgüt kültürünün örgütsel sinizmin önüne geçilmesi için kurulması gerektiğinin altı çizilmiştir (Güleç, Cankul, Yılmaz, 2019).

Gül Gün (2016) tarafindan yapılan araştırmada ise Bitlis’teki otellerde çalışan kişiler üzerinde örgüt kültürü çeşitlerinin örgütsel sinizme etkisi incelenmiştir. Bu çalışmanın amac1; çalışanların örgüt sinizmi ile örgüt kültürü arasındaki ilişkinin demografik özelliklere, örgüte ve örgütteki çalışma süresine göre farklılaşıp farklılaşmadığını öğrenmek ve tutumlarına etkisini görmektir. Veri toplamak için anket yöntemine başvurulmuştur. Araştırma evreni, Bitlis'teki 3 ve 4 yıldızlı otel çalışanlarıdır. Bu tanıma uyan çalışan sayısı 99'dur. Hepsi ankete dahil olmuştur. $\mathrm{Bu}$ çalışma sonucunda; yenilikçi ve destekleyici örgüt kültürünün örgütsel sinizm algısını olumsuz yönde etki ettiği, bürokratik örgüt kültürünün örgütsel sinizm algısını olumlu yönde etkilediği görülmüştür (Gün, 2016).

Murat Tatlı ve Ferda Üstün (2018) tarafından hazırlanan çalışmada yetenek yönetiminin örgütsel sinizme etkisi ve bu etkide örgüt kültürünün rolü incelenmiştir. Çalışma Aksaray’daki kamu çalışanlarına yapılmıştır. Çalışmanın evreni olarak Aksaray defterdarlığında çalışan kişiler seçilmiştir. 151 anket dağıtılmasına rağmen 100 tanesi geri dönmüş ve bu anketler çalışmaya dahil edilmiştir. Çalışma sonucunda örgütsel sinizmin yetenek yönetimi tarafından olumlu ve anlamlı bir şekilde etkilendiği belirlenmiştir. Ayrıca örgüt kültürünün bağımlı ve bağımsız değişkenin ilişkisinde düzenleyici rolü olduğu tespit edilmiştir (Tatlı ve Üstün, 2018).

\section{Araştırmanın Yöntemi}

\section{Araştırmanın Amacı}

Araştırma ve yayın etiğine uyularak gerçekleştirilen bu araştırmanın amacı, Bursa ilinin Karacabey ilçesinde gıda sektöründe çalışan kişilerin örgüt kültürü algılarının örgütsel sinizm tutumlarına etkisini ortaya koymaktır. 


\section{Araștırmanın Evreni ve Örneklemi}

Araştırmanın evreni, 2019 yılı Kasım ayında Bursa ilinin Karacabey ilçesinde gıda sektöründe faaliyet gösteren 4 firmanın çalışanlarıdır. Araştırmanın örneklemini ise bu 4 firmanın herhangi birinde çalışan ve anketleri eksiksiz bir şekilde tamamlayan toplam 110 kişi oluşturmuştur. Anketi dolduran kişi sayısı 117 kişi olmasına rağmen, katılımcılardan 7'si yanlış veya eksik doldurulduğu için bu 7 anket çalışmanın örneklemine dâhil edilmemiştir.

\section{Araştırma Modeli}

Araştırmanın amacı örgüt kültürü aile örgütsel sinizm arasındaki ilişkiyi ortaya koymak olduğu için ilişkisel tarama modeli kullanılmıştır. İlişkisel tarama modelinde değişkenler arasında ilişkinin olup olmadığı ve varsa o ilişkinin güçlü veya zayıf olmasına bakılır (Karasar, 1994). Bu ilişkinin varlığı ve derecesini öğrenmek için korelasyon ve regresyon analizlerine başvurulur. Böylelikle varsa o ilişkinin güçlü mü zayıf mı olduğu anlaşılır.

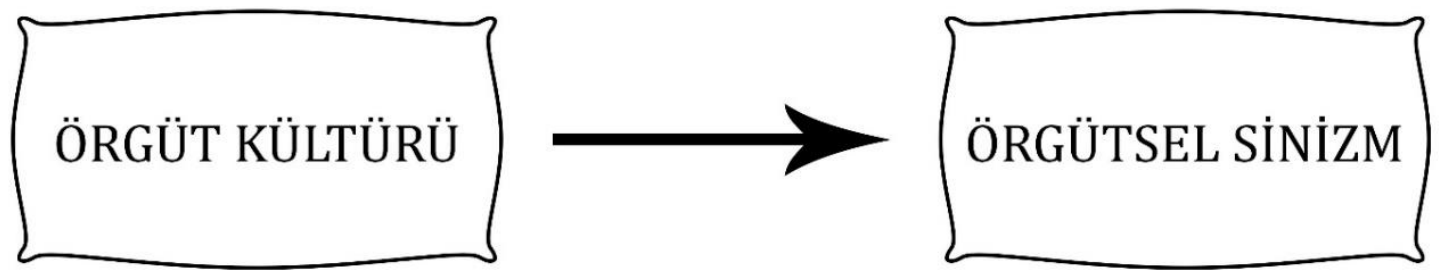

Şekil 1. Araştırmanın Modeli

\section{Araştırmanın Hipotezleri}

Aşağıdaki hipotezler sosyal değişim kuramı 1şı̆̆ında geliştirilmiştir.

H1: Örgüt kültürü ile örgütsel sinizm arasında anlamlı bir ilişki vardır.

H2: Örgüt kültürü alt boyutlarından olan güç kültürü örgütsel sinizme etki eder.

H3: Örgüt kültürü alt boyutlarından olan başarı kültürü örgütsel sinizme etki eder.

H4: Örgüt kültürü alt boyutlarından olan destek kültürü örgütsel sinizme etki eder.

H5: Örgüt kültürü alt boyutlarından olan hiyerarşi kültürü örgütsel sinizme etki eder.

\section{Veri Toplama Aracı}

Veri toplamak için anket yöntemine başvurulmuştur. Anketler yüz yüze gerçekleştirilmiştir. Ankette toplam 34 soru vardır. Anket içerisinde 16 soru örgüt kültürü ile ilgili 13 soru örgütsel sinizm ile ilgilidir. Kalan 5 soru anketleri cevaplayan kişilerin demografik özelliklerini öğrenmeye yöneliktir. Bu demografik sorular yaş, cinsiyet, medeni durum, eğitim düzeyi ve örgütteki çalışma süresi ile ilgilidir.

\section{Araştırmada Kullanılan Ölçekler}

Ankette 2 ölçek kullanılmıştır. Bunlar ilki Örgüt Kültürü Ölçeği’dir. Bu ölçek Cameron ve Freeman'ın 1991'de hazırladığı çalışmadan esas alınmıştır. (Cameron ve Freeman, 1991). 
Ölçek içerisinde 4 alt boyut vardır. Bunlar güç kültürü, başarı kültürü, destek kültürü ve hiyerarşi kültürüdür. Türkçe'ye çevrilmiş olan bu ölçek ve soruları Necdet Sezal'ın çalışmasından alınmıştır (Sezal, 2019). Anket içerisinde her bir alt boyuta ait sırasıyla 4'er soru yer almaktadır.

Diğer ölçek Dean, Dharwadkar ve Brandes (1998) tarafından geliştirilmiş örgütsel sinizm ölçeği 13 sorudan oluşmuştur. (Dean ve diğer, 1998). Türkçe’ye çevrilmiş olan bu ölçek ve soruları Murat Görmen'in çalışmasından alınmıştır (Görmen, 2012). Bu ölçek, aslında 14 sorudan oluşan örgütsel sinizm ölçeğinin yeniden düzenlenmiş halidir. Davranışsal boyutla ilgili 1 soru yeni düzenleme ile çıkartıldığı için soru sayısı 14'ten 13'e düşmüştür.

Bu iki ölçeğe ait 29 soruda Kesinlikle Katılmıyorum (1), Katılmıyorum (2), Kararsızım (3), Katılıyorum (4) ve Kesinlikle Katılıyorum (5) olmak üzere beşli Likert tipi derecelendirme kullanılmıştır.

\section{Bulgular}

\section{Demografik Özelliklerine Göre Katılımcıların Frekans Dağılımı}

Bu bölümde anket katılımcılarının demografik özelliklere göre dağılımları verilmiştir.

\section{Cinsiyete Göre Katılımcıların Frekans Dağılımı:}

Tablo-1: Katılımcıların Frekans Analizine Göre Cinsiyet Dağılımı

\begin{tabular}{ccccc}
\hline Cinsiyet & Frekans & Yüzde & Geçerli Yüzde & Kümülatif Yüzde \\
\hline Erkek & 58 & 52,7 & 52,7 & 52,7 \\
Kadın & 52 & 47,3 & 47,3 & 100,0 \\
Toplam & 110 & 100,0 & 100,0 & \\
\hline
\end{tabular}

Cinsiyet frekans dağılımı analizine göre ankete katılanların \%52,7'si erkek, \%47,3’ü kadındır. Yani erkek sayısı kadın sayısından daha fazladır.

\section{Yaşa Göre Katılımcıların Frekans Dağılımı:}

Tablo-2: Katılımcıların Frekans Analizine Göre Yaş Dağılımı

\begin{tabular}{ccccc}
\hline Yaş & Frekans & Yüzde & Geçerli Yüzde & Kümülatif Yüzde \\
\hline $19-25$ yaş & 25 & 22,7 & 22,7 & 22,7 \\
26-30 yaş & 24 & 21,8 & 21,8 & 44,5 \\
31-35 yaş & 21 & 19,1 & 19,1 & 63,6 \\
36-40 yaş & 14 & 12,7 & 12,7 & 76,4 \\
41 yaş ve üzeri & 26 & 23,6 & 23,6 & 100,0 \\
Toplam & 110 & 100,0 & 100,0 & \\
\hline
\end{tabular}

Yaş frekans dağılımı analizine göre ankete katılanların \%22,7'si 19-25 yaş, \%21,8'i 2630 yaş, \%19,1'i 31-35 yaş, \%12,7'si 36-40 yaş arasında ve \%23,6's1 41 yaş ve üzerindedir. Yani ankete katılanlar en fazla 41 yaş ve üzeri, en az 36-40 yaş arası kişilerden oluşmaktadır. 


\section{Medeni Duruma Göre Katılımcıların Frekans Dağılımı:}

Tablo-3: Katılımcıların Frekans Analizine Göre Medeni Durum Dağılımı

\begin{tabular}{ccccc}
\hline & Frekans & Yüzde & Geçerli Yüzde & Kümülatif Yüzde \\
\hline Bekâr & 50 & 45,5 & 45,5 & 45,5 \\
Evli & 60 & 54,5 & 54,5 & 100 \\
Toplam & 110 & 100,0 & 100,0 & \\
\hline
\end{tabular}

Medeni durum frekans dağ 11 เıı analizine göre ankete katılanların \%45,5'i bekâr, \%54,5'i evlidir. Yani evli kişi sayısı ve bekar kişi sayısından fazladır.

\section{Eğitim Düzeyine Göre Katılımcıların Frekans Dağılımı:}

Tablo-4: Katılımcıların Frekans Analizine Göre Eğitim Durumu Dağılımı

\begin{tabular}{ccccc}
\hline & Frekans & Yüzde & Geçerli Yüzde & Kümülatif Yüzde \\
\hline İlköğretim & 1 &, 9 &, 9 &, 9 \\
Ortaokul & 4 & 3,6 & 3,6 & 4,5 \\
Lise & 31 & 28,2 & 28,2 & 32,7 \\
Ön lisans & 8 & 7,3 & 7,3 & 40,0 \\
Lisans & 56 & 50,9 & 50,9 & 90,9 \\
Yüksek Lisans & 6 & 5,5 & 5,5 & 96,4 \\
Doktora & 4 & 3,6 & 3,6 & 100,0 \\
Toplam & 110 & 100,0 & 100,0 & \\
\hline
\end{tabular}

Eğitim durumu frekans dağılımı analizine göre ankete katılanların \%0,9'u ilköğretim, \%3,6'si ortaokul, \%28,2'si lise, \%7,3'ü ön lisans, \%50,9'u lisans, \%5,5', yüksek lisans ve \%3,6's1 doktora mezunudur. Buna göre ankete en çok lisans mezunu en az ise ilköğretim mezunu katılmıştır.

\section{Çalışma Sürelerine Göre Katılımcıların Frekans Dağılımı:}

Tablo-5: Katılımcıların Frekans Analizine Göre Kurumdaki Çalışma Süreleri

\begin{tabular}{ccccc}
\hline & Frekans & Yüzde & Geçerli Yüzde & Kümülatif Yüzde \\
\hline 1 Y1ldan Az & 23 & 20,9 & 20,9 & 20,9 \\
1-5 Y1l Aras1 & 49 & 44,5 & 44,5 & 65,5 \\
6-10 Y1l Aras1 & 18 & 16,4 & 16,4 & 81,8 \\
11-15 Y1l Aras1 & 8 & 7,3 & 7,3 & 40,0 \\
16 Y1l ve Üzeri & 12 & 10,9 & 10,9 & 100,0 \\
Toplam & 110 & 100,0 & 100,0 & \\
\hline
\end{tabular}

Kurumdaki çalışma süreleri frekans dağılımı analizine göre ankete katılanların \%20,9’u 1 yıldan az, \%44,5'i 1-5 yıl arası, \%16,4'ü 6-10 y1l arası, \%7,3'ü 11-15 yıl aras1 ve \%10,9'u 16 ve daha fazla yıldır şu an ki çalıştığı kurumda çalışmaya devam etmektedir. Yani 1-5 yıl arası çalışan kişi sayısı en fazla, 11-15 yıl arası çalışan kişi sayısı en azdır. 


\section{Örgüt Kültürü ve Örgütsel Sinizm Ölçeklerinin Aritmetik Ortalamaları, Standart Sapmaları ve Çarpıklık-Basıklık Değerleri}

Tablo-6: Ölçeklerin Aritmetik Ortalamaları, Standart Sapmaları ve Normallik Değerleri

\begin{tabular}{|c|c|c|c|c|c|c|c|c|c|}
\hline & \multirow{2}{*}{$\begin{array}{l}\text { Toplam } \\
\text { Değer }\end{array}$} & \multirow{2}{*}{$\begin{array}{l}\text { Min. } \\
\text { Değer }\end{array}$} & \multirow{2}{*}{$\begin{array}{l}\text { Maks. } \\
\text { Değer }\end{array}$} & \multirow{2}{*}{$\begin{array}{l}\text { Art. } \\
\text { Ort. } \\
\text { Değer }\end{array}$} & \multirow{2}{*}{$\begin{array}{c}\text { Standart } \\
\text { Sapma } \\
\text { Değer }\end{array}$} & \multicolumn{2}{|c|}{ Çarpıklık } & \multicolumn{2}{|c|}{ Basıklık } \\
\hline & & & & & & Değer & $\begin{array}{c}\text { Standart } \\
\text { Hata }\end{array}$ & Değer & $\begin{array}{c}\text { Standart } \\
\text { Hata }\end{array}$ \\
\hline $\begin{array}{c}\text { Örgüt } \\
\text { Kültürü }\end{array}$ & 110 & 1,69 & 4,25 & 3,2977 & ,51726 &,- 760 & ,230 & ,229 & ,457 \\
\hline $\begin{array}{l}\text { Örgütsel } \\
\text { Sinizm }\end{array}$ & 110 & 1,00 & 4,31 & 2,6643 & ,84076 & ,351 & ,230 &,- 910 & , 457 \\
\hline
\end{tabular}

Örgüt kültürünün aritmetik ortalaması 3.29, örgütsel sinizmin 2,66'dır. Normal dağılım konusunda ise Tabachnick ve Fidell'e göre çarpıklık-basıklık değerleri -1,5 ile $+1,5$ değerleri arasında olursa ölçek içerisinde normal dağılım vardır (Tabachnick ve Fidell, 2013). Anket içerisinde kullanılan her 2 ölçeğe ait çarpıklık-basıklık değerleri belirtilen aralık içerisinde yer aldığ için verilerin normal dağılım gösterdiği söylenebilir.

\section{Ölçeklerin Güvenilirlik Testleri}

Tablo-7: Örgüt Kültürü Ölçeği Güvenilirlik İstatistikleri

\begin{tabular}{ccc}
\hline Cronbach Alfa & $\begin{array}{c}\text { Standartlaştırılmış Ögelere } \\
\text { Dayanan Cronbach Alfa }\end{array}$ & Öge Sayısı \\
\hline 0,703 & 0,729 & 16 \\
\hline
\end{tabular}

16 maddeden oluşan örgüt kültürü ölçeğinin güvenilirlik analizi, Cronbach alfa sayısına bakılarak incelenmiştir. Örgüt kültürü ölçeğinin güvenilirlik değeri 0,703 'tür. Bu değer örgüt kültürü ölçeğine ait 16 maddenin güvenilirlik değerini göstermektedir. Ölçeğe ait olan güvenilirlik değeri kabul edilebilir değerden yani 0,70’ten fazladır (Gürbüz ve Şahin, 2018; Nunnally, 1978).

Tablo-8: Örgütsel Sinizm Ölçeği Güvenilirlik İstatistikleri

\begin{tabular}{ccc}
\hline Cronbach Alfa & $\begin{array}{c}\text { Standartlaştırılmış Ögelere } \\
\text { Dayanan Cronbach Alfa }\end{array}$ & Öge Sayısı \\
\hline 0,909 & 0,907 & 13 \\
\hline
\end{tabular}

13 maddeden oluşan örgütsel sinizm ölçeğinin güvenilirlik analizi, Cronbach alfa sayısına bakılarak incelenmiştir. Örgüt kültürü ölçeğinin güvenilirlik değeri 0,909'dur. Bu değer örgütsel sinizm ölçeğine ait 13 maddenin güvenilirlik değerini göstermektedir. Ölçeğe ait güvenilirlik değeri kabul edilebilir değerden yani 0,70’ten fazladır (Gürbüz ve Şahin, 2018; Nunnally, 1978). 


\section{Korelasyon Analizi}

Tablo-9: Değişkenlerin Korelasyon Değerleri

\begin{tabular}{c|lcc}
\hline \multicolumn{2}{c}{} & Örgüt Kültürü & Örgütsel Sinizm \\
\hline \multirow{3}{*}{ Örgüt Kültürü } & Pearson Korelasyonu & 1 & $-0,513^{* *}$ \\
& Anlamll1k Oran1 & & 0,000 \\
& Toplam Kişi Sayı1 & 110 & 110 \\
\hline
\end{tabular}

**Korelasyon 0,01 seviyesinde anlamlıdır.

$\mathrm{Bu}$ çalışma içerisinde yer alan örgüt kültürü ile örgütsel sinizm arasında anlamlı bir ilişkinin var olup olmadığı korelasyon analizi ile test edilmiştir. Bu analize göre anlamlılık oranı 0,05’ten küçük olduğu için iki değişken arasında anlamlı bir ilişki olduğunu görüyoruz. Böylece H1 hipotezi (Örgüt kültürü ile örgütsel sinizm arasında anlamlı bir ilişki vardır.) kabul edilmiştir. Bununla birlikte 2 değişken arasındaki korelasyon değerinin negatif olması $(-0,513)$ iki değişken arasında negatif bir ilişki olduğunu gösterir. Ayrıca korelasyon katsayısı -0,3 ile -0,7 arasında (0,513 ) olduğu için aralarındaki ilişki orta seviyededir. Örneklem sayısı 200'den az olduğu için faktör analizi yapılmamıştır (Gürbüz ve Şahin 2018).

\section{Regresyon Analizi}

Tablo-10: Çoklu Regresyon Analizi Sonuçları (N=110)

\begin{tabular}{cccccc}
\hline Alt Boyutlar & B & Standart Hata & Beta & $\mathrm{t}$ & $\mathrm{p}$ \\
\hline Güç Kültürü &, 29 &, 71 &, 31 & 8,549 &, 000 \\
Başar1 Kültürü &,- 11 &, 10 &,- 11 & 4,075 &, 000 \\
Destek Kültürü &,- 05 &, 09 &,- 05 & $-1,098$ &, 275 \\
Hiyerarşi &,- 36 &, 09 &,- 40 &,- 519 &, 605 \\
Kültürü & & & & & \\
Sabit & 3,61 &, 42 & & $-3,892$ &, 000 \\
\hline
\end{tabular}

$\mathrm{R}^{2}=0,54$, Düz. $\mathrm{R}^{2}=0,52, \mathrm{~F}_{(4,105)}=31,654, \mathrm{p}<0.05$

Örgüt kültürü alt boyutlarından güç kültürünün, başarı kültürünün, destek kültürünün ve hiyerarşi kültürünün örgütsel sinizme ne kadar etki ettiğini belirlemek amacıyla çoklu regresyon analizi yapılmıştır. Boyutlara ait değerler Tablo-10'da gösterilmiştir.

Çoklu regresyon analizi sonuçları istatistiksel olarak anlamlıdır. $\left(\mathrm{F}_{(4,105)}=31,654, \mathrm{p}<0.05\right)$ Düzeltilmiş $\mathrm{R}^{2}$ değeri 0,52 'dir. Bu sonuç örgütsel sinizmdeki $\% 52$ oranındaki boyutların güç, başarı, destek ve hiyerarşi kültürü tarafından açıklandığını gösterir. Ancak tüm alt boyutlar regresyona dahil edildiğinde örgütsel sinizmi açılamada sadece güç ve hiyerarşi kültürlerinin anlamlı katkısı olduğunu görüyoruz. Bu durumda, H2 hipotezi (Örgüt kültürü alt boyutlarından olan güç kültürü örgütsel sinizme etki eder.) ve H3 hipotezi (Örgüt kültürü alt boyutlarından olan başarı kültürü örgütsel sinizme etki eder.) desteklenmiştir. Bununla birlikte örgütsel sinizm ile güç kültürü arasındaki regresyon değerinin pozitif olması güç kültürünün örgütsel sinizme pozitif etki ettiğini, başarı kültürünün örgütsel sinizme negatif etki ettiğini gösterir. Ancak destek ve hiyerarşi kültürlerinin örgütsel sinizm üzerinde anlamlı etkisinin olmadığı tespit edilmiştir. Bu durumda, H4 hipotezi (Örgüt kültürü alt boyutlarından olan destek kültürü örgütsel sinizme etki eder.) ve H5 hipotezi (Örgüt kültürü alt boyutlarından olan hiyerarşi kültürü örgütsel sinizme etki 
eder.) reddedilmiştir. Dolayısıyla örgütsel sinizme destek ve hiyerarşi kültürlerinin anlamlı etkisinin olmadığ 1 ifade edilebilir.

\section{Sonuç ve Öneriler}

Çalışmanın sonucunda örgüt kültürü ile örgütsel sinizm arasında anlamlı ve negatif bir ilişki olduğu görülmüştür. Yani araştırmadaki H1 hipotezi kabul edilmiştir. Bununla beraber örgüt kültürü alt boyutlarından güç kültürü ve başarı kültürünün örgütsel sinizmi açıklamada anlamlı katkı sağladığ1 tespit edilirken, örgüt kültürü alt boyutlarından destek kültürü ve hiyerarşi kültürünün örgütsel sinizmi açıklamada anlamlı katkı sağlamadığı tespit edilmiştir. Ayrıca güç kültürünün örgütsel sinizm üzerinde pozitif bir etkisinin olduğu, başarı kültürünün ise örgütsel sinizm üzerinde negatif bir etkisinin olduğu saptanmıştır. Bu açıklamalar doğrultusunda, H2 ve H3 hipotezlerinin desteklendiğini, H4 ve H5 hipotezlerinin ise desteklenmediğini söylemek mümkündür.

$\mathrm{Bu}$ çalışmanın sonuçları 1şığında gıda sektöründeki firmalara bazı önerilerde bulunulabilir. Mevcut çalışmada, örgüt kültürü arttıkça örgütsel sinizmin azaldığını bulgulanmıştır. Çalışanlar örgüt içerisinde kendilerini o örgüte ait hissettirecek bir ortama sahip olursa, örgüte karşı sinik tavırlarının azalacağı öngörülmektedir. Çalışmada örgüt kültürünün boyutlarından güç kültürü arttıkça örgütsel sinizmin de artacağı tespit edilmiştir. Bu doğrultuda, örgütte gücün belirli kişilerde toplanması ve çalışanlar arasında sınırlı ve emredici davranışların olması, örgütte sinik tavırların artmasına etki edebileceği ifade edilebilir. Örgüt içerisindeki başarı kültürünün artmasının örgütsel sinizm üzerinde azaltıcı etkisinin olduğu mevcut çalışmada saptanmıştır. $\mathrm{Bu}$ açıdan, örgüt içerisinde çalışanlar başarı odaklı bir şekilde verilen işlere odaklanır ve verilen işler onları tatmin ederse bu çalışanlar kendilerini mutlu hissedip örgüt hakkındaki sinik tavırlarını azaltabilirler. Özetle, çalışanların örgüt içerisinde yaptıkları işlerin ve sorumlulukların belirgin olması ve işlerinde kendilerini başarılı hissetmelerinin örgütteki sinik tavırları azaltabileceği ileri sürülebilir. Firmalar, örgüt kültürü boyutlarından destek ve hiyerarşi kültürü yerine güç ve başarı kültürüne odaklanırlarsa örgüt içerisindeki sinizmi azaltabilirler.

Literatür taraması bölümündeki çalışmalarla mevcut çalışmanın sonuçları arasında benzerlikler olduğu söylenebilir. Bu açıdan çalışma sonuçlarının literatürde yapılan çalışmalarla tutarlılık gösterdiği ifade edilebilir. Sadece bazı çalışmalarda farklı örgüt kültürü boyutlarıyla örgütsel sinizmin ilişkisi incelendiğinde farklı sonuçlar gözlemlenmiştir.

Her araştırmada olduğu gibi bu araştırmanın da birtakım kısıtları mevcuttur. $\mathrm{Bu}$ kısıtlardan ilki, araştırmanın sadece Bursa ilinin Karacabey ilçesindeki gıda sektörü çalışanlarına yönelik olmasıdır. Bundan dolayı, mevcut araştırma modeli kapsamında yapılacak diğer araştırmalarda farklı evren ve örneklem seçildiğinde sonuç da farklı olabilir. Bir diğer kısıt ise zaman kısıtıdır. Araştırmada, belli bir zaman sınırlaması içinde seçilen evren ve örneklemden 
verilerin toplanması gerektiği için zaman kısıtının olduğu söylenebilir. Zaman kısıtlaması olmasaydı evreni daha iyi temsil edebilecek örneklem analize dâhil olabilirdi. Gelecek çalışmalarda örneklem sayısı arttırılabilir. Ayrıca, örgütsel sinizme etki eden başka faktörler de modele dâhil edilip araştırılabilir, örgüt kültürü ile örgütsel sinizm arasındaki ilişkiyi durumsal olarak etkileyebilen değişkenler de araştırılabilir.

\section{Kaynakça}

Abraham, R. (2000). Organizational Cynicism: Bases and Consequences. Genetic, Social, and General Psychology Monographs, 126(3), 269-292.

Cameron, K.S., ve Freeman S.J. (1991). Cultural Congruence, Strength and Type: Relationships to Effectiveness. Research in Organizational Change and Development, 5, 23-58.

Dean Jr, J.W., Brandes, P. ve Dharwadkar, R., (1998). Organizational Cynicism. The Academy of Management Review, 23(2), 341-352.

Durrah, O., Chaudhary, M., ve Gharib, M. (2019). Organizational Cynicism and Its Impact on Organizational Pride in Industrial Organizations. International Journal of Environmental Research and Public Health, 16(7), 1203.

Goromonzi, W.O., (2016). Organizational Culture, Strategy Implementation and Commercial Bank Performance in Zimbabwe. International Review of Management and Marketing, 6(2), 307-316.

Görmen, M. (2012). Örgüt Kültürünün Örgütsel Sinizm Tutumlarl Üzerine Etkisi ve Bir Uygulama. Yayınlanmamış Doktora Tezi, Gazi Üniversitesi Sosyal Bilimler Enstitüsü, Ankara.

Görmen, M. (2017). Örgüt Kültürünün Örgütsel Sinizm Tutumları Üzerine Etkisi, Bartın Üniversitesi İktisadi ve İdari Bilimler Fakültesi Dergisi, 8(15), 363-388.

Güleç, E., Cankul, İ.H., ve Yılmaz S. (2019). Örgüt Kültürünün Örgütsel Sinizme Etkileri: Kamu ve Özel Hastanelerin Karşılaştırılması. International Anatolia Academic Online Journal/Social Science Journal, 5(2), 116-128.

Gün, G., (2016). Örgüt Kültürü Tiplerinin Örgütsel Sinizm Algısına Etkisi: Bitlis İli Otel İşletmelerinde Bir Alan Araştırması. Bitlis Eren Üniversitesi İktisadi Ve İdari Bilimler Fakültesi Akademik İzdüşüm Dergisi, 1(1), 28-55.

Gürbüz, S., ve Şahin, F. (2018). Sosyal Bilimlerde Araştırma Yöntemleri. Ankara: Seçkin Yayıncilik.

Işık, R. (2014). Örgüt Kültürü, Fonksiyonları, Unsurları ve Boyutları: Dicle Üniversitesi Tıp Fakültesi Hastaneleri Örneği. Yayınlanmamış Yüksek Lisans Tezi, Beykent Üniversitesi Sosyal Bilimler Enstitüsü, İstanbul. 
Kantarcıoğlu, J. (2016). Örgüt Kültürü ile Örgütsel Sinizmin İlişkisi: Ermeni Azınlık Okulları. Yayınlanmamış Yüksek Lisans Tezi, Bahçeşehir Üniversitesi Eğitim Bilimleri Enstitüsü, İstanbul.

Kaya N., Ergün, E., ve Kesen, M. (2014). The Effects of Human Resource Management Practices and Organizational Culture Types on Organizational Cynicism: An Empirical Study in Turkey. British Journal of Arts and Social Sciences, 17(1), 43-61.

Nunnally, J.C. (1978). Psychometric Theory. USA: Mc-Graw-Hill.

Rabiea, N., Karimi, F., ve Sadigh A. N. (2016). The Effect of Transformational Leadership Style and Organizational Culture on the Formation of Organizational Cynicism in the Agricultural Bank of Tehran. Management Science Letters, 6(6), 443-454.

Schein, E.H., (2004). Organizational Culture and Leadership, Jossey-Bass, Third Edition, (s. 437). San Francisco.

Sezal, N. (2019). Örgüt Kültürünün, Örgütsel Bağlllık ve Örgütsel Tükenmişlik Üzerine Etkisi: Kahramanmaraş Tekstil Sektörü Üzerine Bir Uygulama. Yayınlanmamış Doktora Tezi, Selçuk Üniversitesi Sosyal Bilimler Enstitüsü, Konya.

Şişman, M. (2002). Örgütler ve Kültürler. Ankara: Pegem A Yayıncılık.

Tabachnick B.G., ve Fidell L.S. (2013). Using Multivare Statistics, 6th Kindle Edition, USA.

Tatlı, M., ve Üstün, F. (2018). Yetenek Yönetiminin Örgütsel Sinizm Üzerindeki Etkisinde Örgüt Kültürünün Düzenleyici Rolü. İşletme Araştırmaları Dergisi, 10(3), 892-918.

Terzi, A.R. (2000). Örgüt Kültürü. Ankara: Nobel Yayıncıllk.

Topal Yıldırım, D. (2016). Örgüt Kültürü ve Örgütsel Sinizm İlişkisi: Sağllk Çalışanlarına Yönelik Bir Araştırma. Yayınlanmamış Yüksek Lisans Tezi, Nişantaşı Üniversitesi, Sosyal Bilimler Enstitüsü, İstanbul.

Yalçınsoy, A. (2019). Örgütsel Sinizmin Nedeni Örgüt Kültürü Müdür? International Journal of Management and Administration, 3(5), 13-20. 